\title{
Open Educational Resources (OER) for Sustainable Development using Autonomic Cloud Computing System
}

\author{
Nureni Asafe Yekini ${ }^{\mathrm{a}}$, Uduak Inyang-Udoh ${ }^{\mathrm{b}}$, Funmilayo Doherty ${ }^{\mathrm{c}}$ \\ ${ }^{a}$ Dept of Computer Engineering, YabaTech, Lagos, Nigeria \\ ${ }^{b}$ Director Academics Planning Unit, YabaTech, Lagos, Nigeria \\ ${ }^{c}$ Coordinator, UNEVOC Center, YabaTech, Lagos, Nigeria
}

\begin{abstract}
Open Educational Resources (OER) are those teaching and learning materials that are available either in the public domain or under an open license. The focus of this research work is to propose a conceptual framework for design and implementation of TVET autonomic cloud-based OERs for it integration into classroom teaching and learning strategies towards sustainable development. The beauty of this proposed system is its autonomous and self-managed features. The system will have capability of including the following: laboratory activities; syllabi, homework and assignment; assessments (CBT- computer-based test), lecture notes; audio visual lectures; simulation; lesson plan; and textbooks etc. while the system will be own and maintained by Yaba college of technology Nigeria, it's services will be available for usage by any individual with interest in TVET across the globe.
\end{abstract}

Index Terms: OERs, TVET, Autonomic Cloud Computing Architecture, classroom teaching, CBT, lecture note, syllabi, sustainable development.

(C) 2016 Published by MECS Publisher. Selection and/or peer review under responsibility of the Research Association of Modern Education and Computer Science.

\section{Introduction}

\subsection{Background to the Study}

OERs Teaching, learning and research materials in any medium, digital or otherwise, that reside in the public domain or have been released under an open license that permits no-cost access, use, adaptation and redistribution by others with no or limited restrictions [1]. One of the major customers of OERs is the students, that access to scholars from all parts of the globe [2].

Technical and Vocational Education and Training (TVET) is concerned with the acquisition of knowledge

* Corresponding author. Tel.:

E-mail address: 
and skills for the world of work. Throughout the course of history, various terms have been used to describe elements of the field that are now conceived as comprising TVET. These include: Apprenticeship Training, Vocational Education, Technical Education, Technical-Vocational Education (TVE), etc. Several of these terms are commonly used in specific geographic areas. Autonomic computing encompasses the study of systems that are capable of autonomously achieving desired behaviors. They are self-tuned systems are capable of turning their performance as needed by their intended mission; self-protected, self-managed. Variety of frameworks, architectures and techniques have been proposed and used in the field of autonomic computing for selfmanagement [3]. Autonomic computing will become omnipresent as the IT world increasingly becomes one where systems have large scale, are built out of existing components and services, are dynamic in space and time, have increasing complexity and connectivity, and are subject to competitive pressures that do not leave room for exponential management costs [4].

In this research work, we present design and implementation of autonomic cloud-based OERs for TVET, while the system is owned by Yaba College of Technology; its services will be open for all individual with interest in technical and vocational education across the globe. The system will be furnished with some features for self-management of it" database resources for TVET sustainability.

\subsection{Aims and Objectives}

The aim of this research work is to design and implement an Open Educational Resource (OERs) for Technical Vocational Education and Training (TVET) for sustainable development using autonomic cloud computing architecture. If the system is designed and implemented the following objectives can be achieve.

- To promote sharing of learning materials by TVET.

- To Increase availability of high quality, relevant learning materials that can contribute to the productivity of students and educators

- To enhance sharing of good quality learning resources in TVET

- To support flexible learning through cloud computing.

- To enhance collaboration among academicians in TVET across the globe.

- To enhance quality assurance of assessment through the use of CBT platform.

- To allow access to huge amounts of data and information, that is adaptable for new uses by other without any legal implication.

- to build capacity by providing institutions and educators access, at low or no cost, to learning materials to develop their competence in producing educational materials and carrying out the necessary instructional design to integrate such materials into high quality programmes of learning.

\subsection{Anticipated Impact}

It is anticipated that the output of this research work will impact in the following areas:

- First, there will be global institutional impact in TVET on teaching and learning, and professional development, in respect of the use of OERs and digital literacy as part of programmes for teachers in TVET institutions.

- The wider higher education community will have opportunities to use the resources through open access. This will enable those who are not engaged in formal programmes of study gain from the project.

- There will be opportunities for knowledge transfer through the involvement of Core Educationist who works in other domains in a not-for-profit capacity. The use of this system by them will be applicable to other contexts for their work.

- Integrating this OER platform into classroom teaching and learning strategies will facilitate impact on the 
pedagogical development of new school teachers. This in turn can be applied in the school situation where OERs may also be used and where digital literacy and creativity are key aspects of the curriculum review.

\section{Related Works}

In the paper entitled understanding open education resources (OER) by [5], he identify the growing problems in education today as Lack of access - Educational materials, and where it is available it is of poor quality, the cost of access in many locations is very high and increases each year. While there are many other reasons to support OER, the cost issue is a primary factor in their growing popularity amongst students and teachers. Open Educational Resources (OER) are vital learning materials with the prospective to facilitate the expansion of learning worldwide. The flexibility, both technological and legal, afforded by openly licensed content is an important precondition for supporting the educational use of content. Open standards support the deployment of learning objects as OER on a wide variety of different devices, whether mobile, on the desktop or in print. The open licence frees instructors and learners from concerns about permissions, as well as about how, when, where and how long the content, video, audio or application can be used [6]. The notch to which Open Educational Resources (OER) reflect the values of its institutional provider depends on questions of economics and the level of support amongst its academics, and the potential motivators for academics in providing OER material, as an understanding of these is helpful when introducing the subject to new contributors, and when informing planning. OER projects do not work in isolation from internal competition and it has been essential to be sensitive to the conflicting pressures that academics have to contend with in their work profile [7].

There are a number of possible OERs models that could be developed, but not all, of which assume a role for universities and related academic institutions. The roles of academic libraries in support of the release and use of OERs is very paramount [8].

The rationale, common practices, challenges, and some personal anecdotes from a journal editor on the production, use, and re-use of peer-reviewed scholarly articles as Open Educational Resources (OER) by [9]. He highlighted the challenges, economic models, and evidence for quality of open access journal content and look at new affordances provided by the Net for enhanced functionality, access, and distribution. He pinpoints the licencing of OPEN Access Schorlar Work with respect to Creative Commons Licenses which includes a number of additional rights that are detailed in the particular license attached to the work as:

- CC BY: The most permissive, and thus open license, restricts rights to copy and share and only requires attribution to the copyright owner - owned BY. This license allows for reuse of the content including modifying, adding, or deleting portions and redistributing in any format.

- CC ND: Some authors and publishers use an additional restriction that stipulates no derivatives such as edits and additions.

- CC NC: The copyright owner can also include a non-commercial restriction that prohibits others from selling or bartering the copyright product.

- CC SA: This share alike restriction allows the user to share the copyright material, if it is relicensed under the same licensing agreement adopted by the copyright owner.

In the paper entitled use of Open Education Resources in higher education programmes of academic practice, the author created a module, with a pedagogic framework to support the deployment and use of OERs to promote and develop digital literacy and creative approaches to teaching and learning in higher education. They pronounced the following objectives: Create an online module framework that will support the use of OERs on digital literacy and creativity; Create and bring together accessible teaching and learning resources (OERs) around digital literacy and creativity; Re-purpose exiting OERs from the Information Technology in Teacher Education (ITTE) community that develop digital literacy and creativity; Create detailed and accessible pedagogic structure for the use of these resources (existing OERs) on digital literacy and creativity; Develop 
and release guidance materials indicating pathways through the resources on digital literacy and creativity [10].

The chronicle of events that Oxford University has made in opening up educational content and the ways in which people have worked to ensure that the value added by technology aligns with current academic practice in the institution was carefully presented in a paper tilted Making Academic OER Easy: Reflections on Technology and Openness at Oxford University by [11].

Cloud computing could be view as the use of computing resources that are delivered as a service over a network (typically the Internet), cloud computing can also be view as fashionable term used to describe the diverse use of information and communications technologies to support and enhance teaching as opine by [12].

\section{Research Methodology}

\subsection{Data Collection Method}

Data collection method adopted in this research work include interview, record inspections via registered TVETs institutions (Polytechnics and Colleges of Technology, Universities of technology) and agencies e.g. NABTEB-= National Business and Technical Examinations Board, NBTE-National Board for Technical Education in Nigeria, and use of information super highway on internet. The primary data (name and address of recognized TVET institutions, available TVETs courses, course syllabi, etc.

\subsection{Data Analysis and Integration}

Let $\mathrm{X}, \mathrm{Y}$, and $\mathrm{Z}$ represent the categories of data/information to be included in the system.

$$
\begin{gathered}
X=\text { non_audio/video } \\
Y=\text { auidio_video } \\
Z=\text { Learning_assesment_materials } \\
X=D x_{1 \ldots n}-------------- \text { eqn } 1 \\
Y=D y_{1 \ldots n}---------------e q n 2 \\
Z=D z_{1 \ldots . n}----------------e q n 3 \\
D B_{C 1}=D x_{1 . . n}+D y_{1 . . n}+D z_{1 . . n}------e q n 4
\end{gathered}
$$

$\mathrm{DB}_{\mathrm{c} 1}$ are resources that will provide the services to be rendered by the system, without its contents the proposed system is useless. Hence the $\mathrm{DB}_{\mathrm{c} 1}$ is most significant value data for the system. $\mathrm{DB}_{\mathrm{c} 1}$ will be managed by human agent1, and system agents are indicated in the proposed block diagram. $\mathrm{DB}_{\mathrm{c} 2}$ is the data from TVET institutions, Agencies or partners; detail of registered users as in TVETs expert/academician, and the students.

$$
\begin{aligned}
& D B_{c 2}=D_{T I}+D_{T A}+D_{T E}+D_{T S}------e q n 5 \\
& D B_{S Y S}=D B_{C 1}+D B_{C 2}----------e q n 6
\end{aligned}
$$

therefore

$$
D B_{S Y S} \approx\left\{\left(D x_{1 . . n)}+D y_{1 \ldots n}+D z_{1 . . n}\right)+\left(D_{T I}+D_{T A}+D_{T E}+D_{T S}\right\}-------e q n 7\right.
$$


Where

$\mathrm{DB}_{\text {sys }}$ the data that will be included in the system, $\mathrm{D}_{\mathrm{TI}}$ is the TVET institutions, $\mathrm{D}_{\mathrm{TA}}$ is the TVETs agencies, $\mathrm{D}_{\mathrm{TE}}$ is the TVET expert/academician, and $\mathrm{D}_{\mathrm{Ts}}$ is the TVET students or learners.

The proposed system is database driven. The list of recognised TVET across the globe will be created by the administrator. When any individual is registering he/she have to choose from the drop down list of registered $\mathrm{D}_{\mathrm{TI}}$ and $\mathrm{D}_{\mathrm{TA}}$. If his $\mathrm{D}_{\mathrm{TI}}$ or $\mathrm{D}_{\mathrm{TI}}$ does not exist he/she have to enter it and clicks submit but his registration will be accredited only when the $\mathrm{D}_{\mathrm{TI}}$ or $\mathrm{D}_{\mathrm{TI}}$ is verified. The $\mathrm{D}_{\mathrm{TS}}$ registration is subjected to accreditation by his/her institution, or lecturer. For utilization of the system resources student's lecturer must be full registered.

\section{Proposed System}

The autonomic cloud-based OERs for TVET cannot completely replace teachers and learning in TVET institutions. It is only an updating for technology, concepts and tools that gives new content, concepts and methods for education, to create an online module framework that will support the use of OERs for productive learning in TVET. The proposed autonomic cloud-based OERs for TVET architecture will be based on interaction and interfacing of different categories of users. Figure 1; illustrate the proposed bock diagram and data flow of the system. There are four agents (three physical agent- human agents, and one virtual agentsystem agent). The flowcharts in figure 2, 3, 4, and 5, give the detail of interaction and interfacing of the user, and serves as pathway for system coding with appropriate system design software. The human agents are the system administrator/s, TVETs expert/academician, and Students of TVET some of the activities of these agents are embedded in figure 1 . While figure 2, 3, 4, and 5 gives the flowchart for agent interaction with the proposed system.

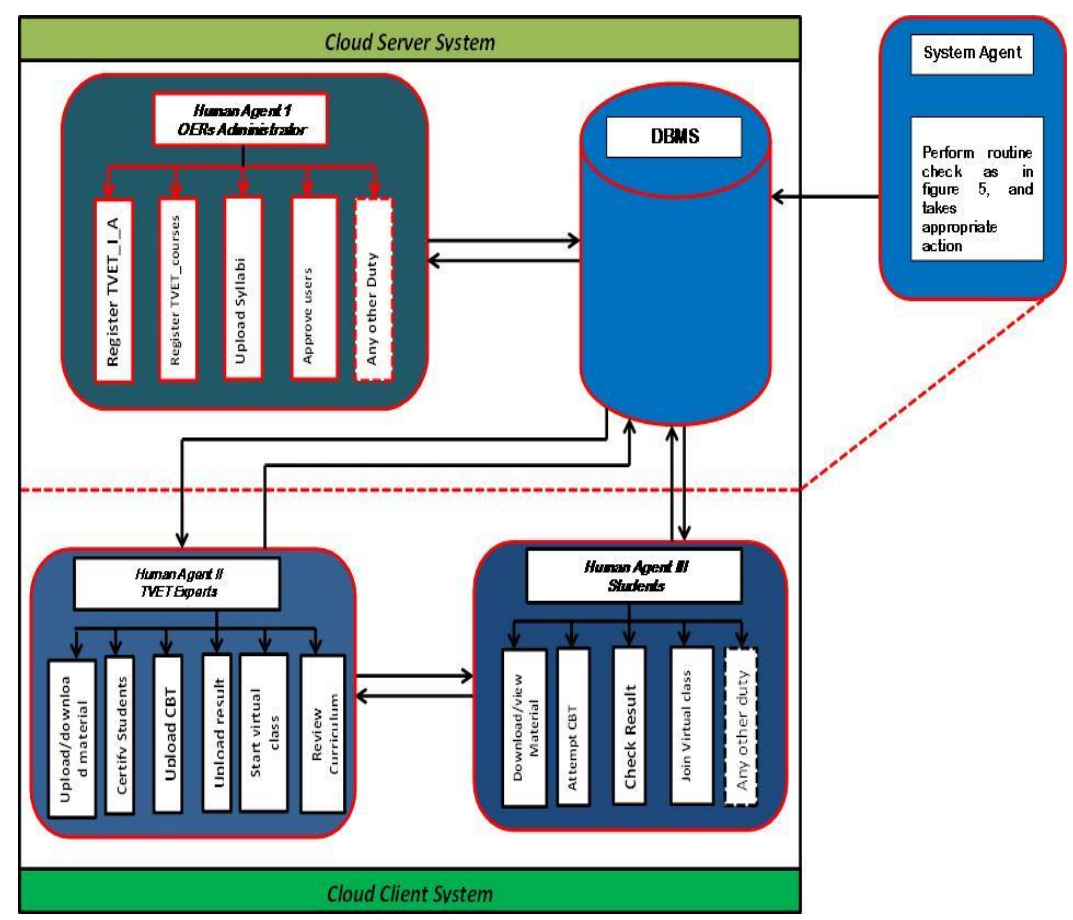

Fig.1. Proposed Bock Diagram and Data Flow of Autonomic Cloud-Based OERs for TVET 


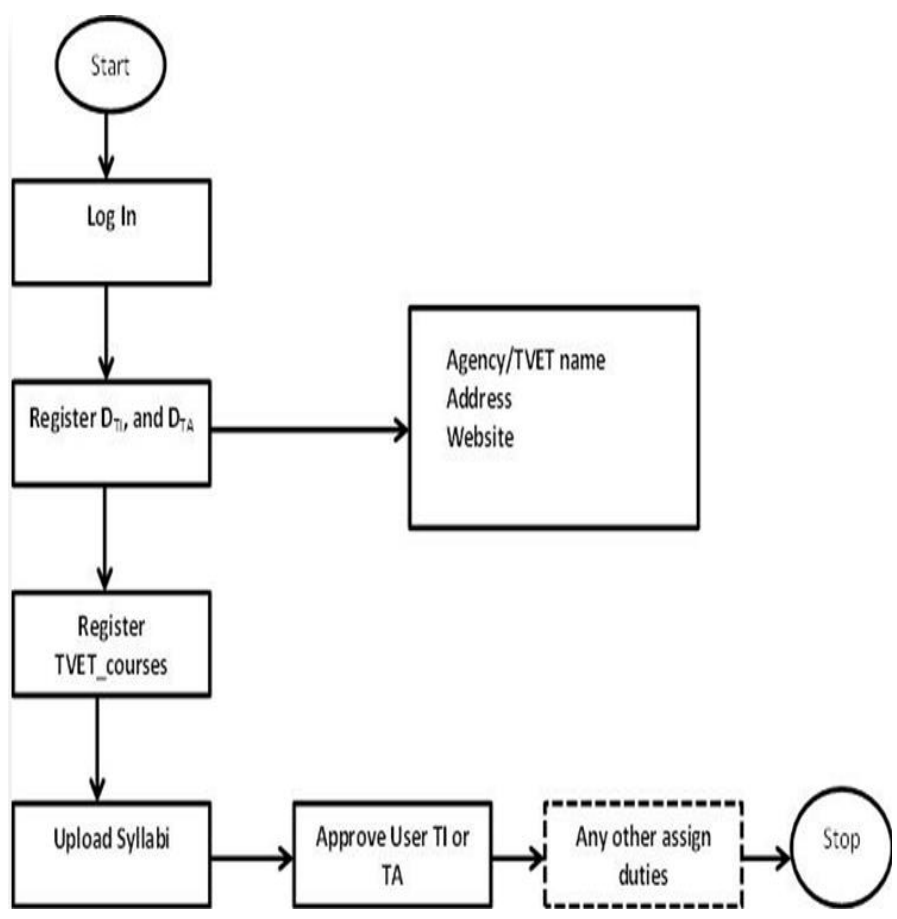

Fig.2. Flowchart for Agent 1 Activities Coding

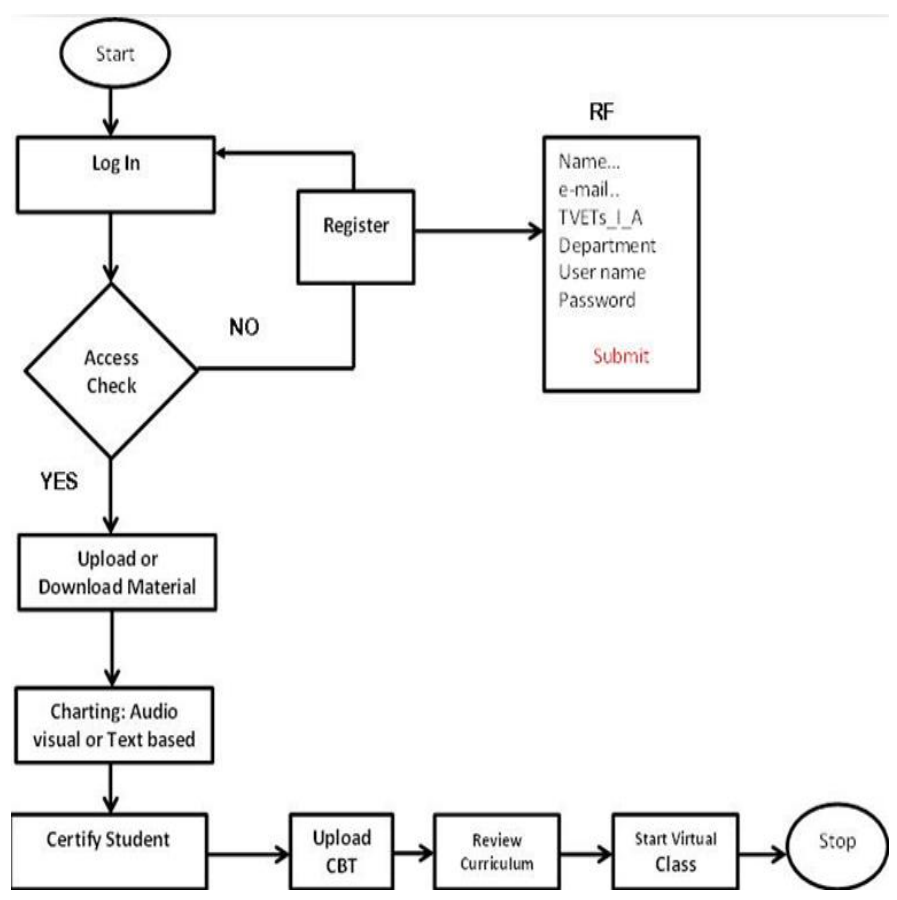

Fig.3. Flowchart for Agent 2 Activities Coding 


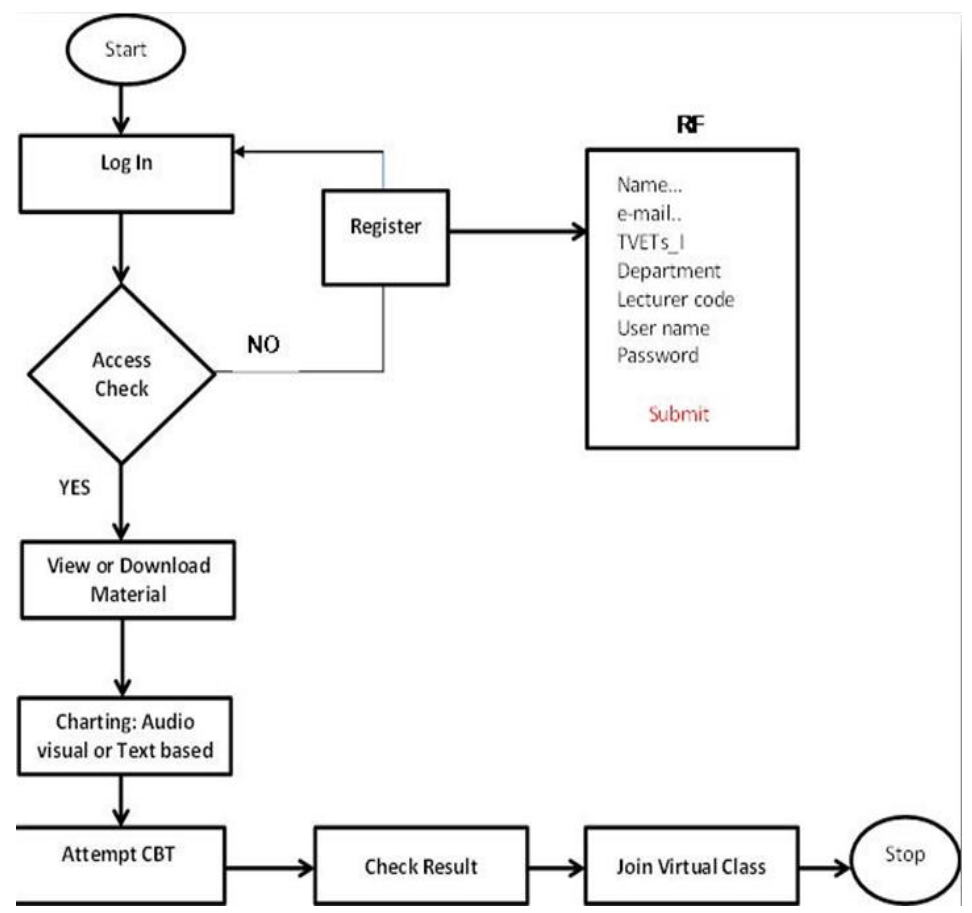

Fig.4. Flowchart for virtual agent Operation Coding

\section{Conclusion}

It is appropriate for a foremost institution with a global brand to be addressing challenges and extending its reach, in recent time. Yaba College of technology has recognized that OER activity is in line with its business, mission and purpose. This alignment is reflected in several case studies included in official institutional strategies towards global reach through the constitution of FSD/FSB champion committee in the college. The availability of this OER platform will contribute to outreach efforts, and place YabaTech internationally in a new light, and academics will be able to participate in extending this reach. Design and implementation of this system will place YabaTech on global revolution in teaching and learning. The experience with OER projects will help to demonstrate that ICT integration in TVET can remove some of the technical, legal, and cost barriers in getting educational resources. Hence enable staff to painlessly embrace new ways of working.

\section{References}

[1] UNESCO (2015): Open Educational Resources. What+is+TVET. Retrieved from http:// www.unesco.org/communication-and-information/access-to-knowledge/open-education-resources Accessed: 18/02/16

[2] Silvertown, J. (2009). A new dawn for citizen science. Trends in Ecology \& Evolution (Personal edition), 24(9), 467-471. from http://linkinghub.elsevier.com/retrieve/pii/S016953470900175X

[3] Khalid A. (2009): Survey of Frameworks, Architectures and Techniques in Autonomic Computing," in Autonomic and Autonomous Systems, 2009. ICAS '09. Fifth International Conference, vol., no., pp.220- 
225, 20-25 April 2009 doi: 10.1109/ICAS.2009.38

[4] Fortes J. (2012): director of the US National Science Foundation's Center for Autonomic Computing. Image courtesy José Fortes. https://sciencenode.org/feature/what-autonomic-computing.php

[5] McGreal R. (2013): The Need for Open Educational Resources. Commonwealth of Learning Prospective on open and distance learning 2013.

[6] Doherty V.F. (2016): understanding open education resources (OER) Yaba College of Technology UNEVOC Centre for Research and Sustainable Development.

[7] Anderson T. (2013): Open Access Scholarly Publications as OER. International review of research in open and distributed learning. Advancing research, theory, and practice in open distributed learning worldwide Athabasca University, Canada.

[8] Highton M., Fresen J, \& Wild J. (n.d): Making Academic OER Easy: Reflections on Technology and Openness at Oxford University. Journal of open, flexible and distance learning.

[9] Bradshaw P, Younie S, \& Jones S. (2012). The Use of Open Education Resources in Higher Education Programmes of Academic Practice. ICICTE 2012 Proceedings.

[10] Roberston R. (2010): What do academic libraries have to do with Open Educational Resources? Theme: Long term sustainability of open education projects. In Open Ed 2010 Proceedings. Barcelona: UOC, OU, BYU. [Accessed: 13/01/16].http://hdl.handle.net/10609/4847

[11] Browne T, Holding R, Howell A, Rodway-Dyer S, (2010). The challenges of OER to Academic Practice. Journal of interactive media in education Volume: 2010, ISSUE: 1.

[12] Oludipe O., Fatoki O. K., Yekini N. A., \& Aigbokhan E. E. "Cloud-Based E-Learning Platform: From the Perspective of 'Structure' and 'Interaction" International Journal of Innovation and Research in Educational Sciences. Volume 1, Issue 1.

\section{Authors' Profiles}

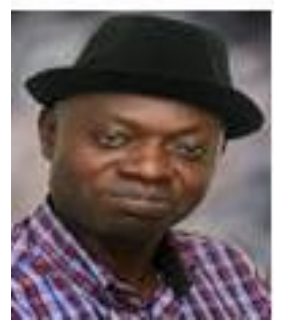

Yekini. N. Asafe is currently a researcher and Lecturer at Yaba College of Technology, Lagos-Nigeria. He was with Computer sciences department for a decade, before he was redeployed to computer engineering in the year 2015. He obtained his academic qualification as follows: M.Sc. in Computer Science, University of Lagos Nigeria (UNILAG); B.Sc. in Electronic and Computer Engineering, Lagos State University (LASU), and NCE (National Certificate in Education) in Physics Lagos State College of Education Ijanikin (LACOED). He is a Member Nigeria Computer Society (NCS), International Association of Engineers (IAENG), International Association of Computer Science and Information Technology (IACSIT), and Member Institute of Electrical Electronic (MIEEE). He is a singular author, and co-author, of several academic/research publications that has features in some revered international journals and conference proceedings both in Nigeria and in abroad. He has writ-ten about seventeen textbooks in computer science and engineering. He is currently the Public Relation Officer II of IEEE Nigeria.

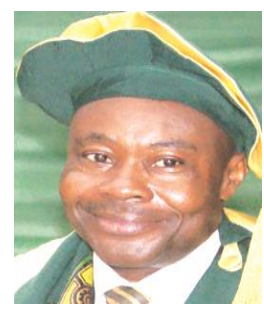

Inyang-Udoh, Uduak Ikpong is a Chief Lecturer B.Sc. Qty Surv; M.Sc. Const. Mgt; Cert. in Site Mgt, and Director of academic planning (APU) at Yaba College of Technology, Yaba, Lagos. He Studied at University Of Lagos, Akoka, Lagos. He is a singular author, and co-author, of several academic/research publications that has features in some revered international journals and conference proceedings both in Nigeria and in abroad. He attended university of Ife now Obafemi Awolowo University, Ile- Ife for his first degree and University of Lagos for his second degree. He obtained certificate in Site 
Management from Crown Agents of London. He is a Fellow of Nigerian Institute of Quantity Surveyors. He is currently a chief lecturer and director of Academic Planning Unit of Yaba College of Technology.

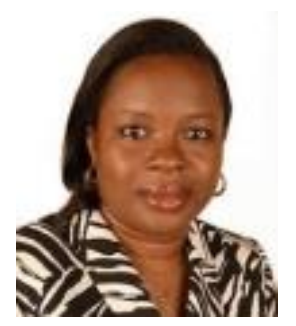

Dr. (Mrs.) V. Funmilayo DOHERTY is an Environmental Toxicologist and a lecturer in the Environmental Biology unit, Yaba College of Technology. She attended Ahmadu Bello University for her Bachelor's degree in Zoology and graduated with a second class upper, She obtained an M.Sc and Ph.D in Environmental Toxicology and Pollution Management from the University of Lagos. She also has a Post Graduate Diploma in Health, Safety and Environmental Management (HSE) from Medilag Consult, University of Lagos, PGD Technology Management from the National Centre for Technology Management (NACETEM), University of Ife.

Dr (Mrs) Doherty is a member of several professional bodies including Society of Environmental Toxicology and Pollution Mitigation (SETPOM), Organization for Women in Science for the developing world (OWSD), European Project funding and Management Academy, Zoological Society of Nigeria (ZSN), International Society for Environmental Information Science and the Nigerian Environmental Society (NES). She is currently the Financial Secretary of the Environmental Research Group (ERG) and Assistant General Secretary of Women in Technical Education (WITED), Yaba College of Technology chapter. She is a member of the editorial board and e-editor of YCT International Journal of Environmental Issues; a member of the Board of Trustees (BOT) and Global Working Council (GWC), Society for Environmental Toxicology and Pollution Mitigation (SETPOM).

How to cite this paper: Nureni Asafe Yekini, Uduak Inyang-Udoh, Funmilayo Doherty,"Open Educational Resources (OER) for Sustainable Development using Autonomic Cloud Computing System", International Journal of Engineering and Manufacturing(IJEM), Vol.6, No.6, pp.60-68, 2016.DOI: 10.5815/ijem.2016.06.06 